Research Article

\title{
Reuse of Zeolite By-Products Derived from Petroleum Refining for Sustainable Roads
}

\author{
M. Sol-Sánchez, ${ }^{1}$ F. Moreno-Navarro ${ }^{(D)},{ }^{1}$ M. C. Rubio-Gámez $\left(\mathbb{D},{ }^{1}\right.$ V. Pérez-Mena, ${ }^{2}$ \\ and P. Cabanillas ${ }^{2}$ \\ ${ }^{1}$ Laboratory of Construction Engineering, University of Granada, C/Severo Ochoa s/n, 18071 Granada, Spain \\ ${ }^{2}$ Cepsa Comercial Petróleo, Carretera de Daganzo Km 5.5 Alcalá de Henares, Madrid, Spain \\ Correspondence should be addressed to F. Moreno-Navarro; fmoreno@ugr.es
}

Received 14 December 2018; Revised 13 February 2019; Accepted 4 March 2019; Published 2 May 2019

Guest Editor: Jose Norambuena-Contreras

Copyright ( 92019 M. Sol-Sánchez et al. This is an open access article distributed under the Creative Commons Attribution License, which permits unrestricted use, distribution, and reproduction in any medium, provided the original work is properly cited.

\begin{abstract}
The reduction in consumption of natural resources (fuel, gas, etc.) and contaminant emissions $\left(\mathrm{CO}_{2}, \mathrm{CO}, \mathrm{NO}_{x}\right.$, etc.) during the production of asphalt mixtures has become one of the main challenges in road engineering. Warm mix asphalts (WMAs) have been developed in order to achieve this objective while ensuring the mechanical performance and durability of traditional hot mix asphalts (HMAs). However, these materials are commonly manufactured using additives or products whose production could reduce both their environmental benefits and cost effectiveness. This paper presents a research study that aims to analyse the reuse of zeolite wastes derived from petroleum refining in the production of warm mix asphalts. For this purpose, two different types of zeolite wastes were analysed as additives for the manufacture of two warm mix asphalts, whose mechanical performance was compared with conventional WMA and hot mix asphalt. The results indicate that zeolite wastes with a lower particles size presented higher capacity to absorb water, while its dosage at $0.3 \%$ allows for producing warm mix asphalts at temperatures around $145^{\circ} \mathrm{C}$, with comparable workability and densification to conventional HMA at $165^{\circ} \mathrm{C}$ without reducing its bearing capacity, fatigue life, and resistance to water action and plastic deformation.
\end{abstract}

\section{Introduction}

Asphalt mixtures are widely used in pavement for roads all around the world. To illustrate, the majority of European roads are composed of this type of pavement [1] due to its constructive benefits and other technical advantages (lower noise levels, flexibility to absorb distresses, etc.). However, the manufacturing of such materials includes a process of heating the components to temperatures higher than 150$160^{\circ} \mathrm{C}$ in order to reduce the viscosity of the binder. This generates harmful fumes during manufacturing in plant and during the transportation and spread process, whilst the significant consumption of energy is also required, leading to negative effects from both economic and environmental standpoints [2].

To reduce such negative effects, it has been shown that decreasing the manufacturing temperature of asphalt mixtures leads to a significant reduction in fuel consumption and emissions of $\mathrm{CO}_{2}$ and volatile organic compounds, amongst other benefits [3]. In addition, decreasing the binder temperature leads to lower loss of volatiles and oxidation of the bitumen (associated with material ageing) during the manufacturing process, resulting in a more viscous material that is less susceptible to brittle failure [4]. In this context, warm mix asphalt (WMA) allows for a reduction in manufacturing temperature of around $20-40^{\circ} \mathrm{C}$ in comparison with conventional hot mix asphalt (HMA), which reduces its negative environmental impacts without compromising its resistance to the main failure modes that occur in bituminous pavements in roads (rutting, stripping, fatigue, etc.) $[5,6]$.

Depending on the technique applied, WMA can be qualified into 3 different categories: incorporation of organic additives (Fischer-Tropsch wax, Montan Wax, etc.) [7, 8] chemical additives (emulsification agents, surfactants, etc.) [9]; and water to produce the foaming of the bitumen 
$[10,11]$. The latter can be conducted by directly injecting water into the bitumen or including particles such as zeolites or hydrophilic fillers that contain water, which is released during the manufacturing process at temperatures usually higher than $120^{\circ} \mathrm{C}$. Nonetheless, all of these technologies also present some limitations that are mainly associated with cost and the consumption of raw materials [12]. Thus, solutions and materials are required that are able to improve the efficiency and potential benefits of these manufacturing technologies.

In this regard, this study analyses the viability of reusing the zeolites as a catalyst during the petroleum refining process (which are wastes), as an industrial by-product in the manufacture of WMA, and then, aiming to reduce costs and consumption of raw materials in the production of WMA. Zeolites are commonly used in the fluid catalytic cracking (FCC) step during the refining process to accelerate the disintegration of heavy molecules of petroleum, thanks to their crystal structure providing channels and chambers to facilitate the interaction of molecules. Nonetheless, after a number of refining processes of petroleum, the zeolites are discarded due to its degradation, and then, size of its pores changes. However, they still conserve the capacity to retain and release water under changing temperature conditions [13-15].

Therefore, zeolite by-products could be appropriate for use in the manufacture of WMA by indirect bitumen foaming, resulting in economic and environmental savings whilst reusing waste materials for the improvement of asphalt mixtures to be used in roads [16]. In the present study, two different types of waste zeolites were firstly characterized according to their requirements for use as additives containing water for WMA manufacture. Following this, the design and performance of two WMAs including both types of subproduct zeolite was compared with conventional WMAs and hot mix asphalt (HMA).

\section{Methodology}

2.1. Materials. For this study, three types of zeolites were studied: two zeolite by-products (referred to in this paper as Zeolite 1 and Zeolite 2) and a commercial zeolite (referred to as Reference Zeolite, and widely used to manufacture WMA). The conventional zeolite consisted of synthetic zeolites, $20 \%$ of whose mass is composed of crystallized water that is released during contact with bitumen at a temperature ranging $85-180^{\circ} \mathrm{C}$ [17]. Regarding the subproduct zeolite, both were obtained from the refining process of petroleum as end-of-life materials that were used as a catalyser with different properties.

Table 1 shows the main physical properties of the zeolite used in this study while, Table 2 represents the composition of the subproduct zeolites, the Reference Zeolite being a sodium-aluminum-silicate hydrothermal crystal. It can be seen that both subproduct zeolites (Zeolite 1 and Zeolite 2) present lower particle size and higher density than the Reference Zeolite, whilst the hygroscopic humidity of this latter material is the highest, followed by Zeolite 1 and Zeolite 2.
TABLE 1: Main physical properties of zeolites.

\begin{tabular}{|c|c|c|c|c|}
\hline \multicolumn{2}{|c|}{ Properties } & \multirow{2}{*}{$\begin{array}{l}\text { Zeolite } 1 \\
\% \text { passing }\end{array}$} & \multirow{2}{*}{$\begin{array}{l}\text { Zeolite } 2 \\
\% \text { passing }\end{array}$} & \multirow{2}{*}{$\begin{array}{c}\text { Reference } \\
\text { Zeolite }\end{array}$} \\
\hline \multirow{5}{*}{ Granulometry } & Size $(\mathrm{mm})$ & & & \\
\hline & 0.5 & 100 & 100 & 100 \\
\hline & 0.25 & 100 & 100 & 83 \\
\hline & 0.125 & 100 & 92 & 64 \\
\hline & 0.063 & 100 & 26 & 40 \\
\hline \multicolumn{2}{|c|}{ Bulk density $\left(\mathrm{mg} / \mathrm{m}^{3}\right)$} & 0.67 & 0.81 & 0.43 \\
\hline \multicolumn{2}{|c|}{$\begin{array}{l}\text { Maximum density } \\
\left(\mathrm{mg} / \mathrm{m}^{3}\right)\end{array}$} & 2.642 & 2.697 & 2.449 \\
\hline \multicolumn{2}{|c|}{ Hygroscopic humidity (\%) } & 0.67 & 0.26 & 3.2 \\
\hline
\end{tabular}

TABLE 2: Composition of subproduct zeolites.

\begin{tabular}{lcc}
\hline Component & Zeolite 1 & Zeolite 2 \\
\hline $\mathrm{P}_{2} \mathrm{O}_{5}(\%)$ & 1.38 & 1.63 \\
Oxides $(\%)$ & 1.63 & 1.64 \\
Calcium $(\mathrm{mg} / \mathrm{kg})$ & 83 & 47 \\
Copper $(\mathrm{mg} / \mathrm{kg})$ & 17 & $<10$ \\
Iron $(\mathrm{mg} / \mathrm{kg})$ & 3.057 & 2.635 \\
Magnesium $(\mathrm{mg} / \mathrm{kg})$ & 164 & 132 \\
Nickel $(\mathrm{mg} / \mathrm{kg})$ & 1.048 & 1.350 \\
Sodium $(\mathrm{mg} / \mathrm{kg})$ & 2.159 & 1.809 \\
Vanadium $(\mathrm{mg} / \mathrm{kg})$ & 502 & 701 \\
\hline
\end{tabular}

To analyse the viability of using subproduct zeolite for the manufacture of asphalt mixtures, a conventional asphalt mixture type AC-22 S (EN 13108-1) was employed since it is commonly utilized in the construction of pavement for roads and during maintenance and rehabilitation operations. The mineral skeleton was composed of limestone aggregates for the different fractions $(0 / 6,6 / 12,12 / 18$, and $18 / 25$ ) from filler to particles with a maximum size of $22 \mathrm{~mm}$, while the bitumen was a conventional B35/50 (whose penetration was equal to $44 \mathrm{dmm}$ according to EN 1426 , with a softening point of approximately $52^{\circ} \mathrm{C}$-EN 1427 ) with a dosage equal to $4.03 \%$ over the total weigh of the mixture. Table 3 summarises the main characteristics of the design of the mixture used as a control (the conventional HMA), which was used to assess the effect of reducing the manufacturing temperature, along with the effectiveness of the zeolites.

Considering this conventional mixture as a reference, the effect of zeolite by-products in WMA manufacturing was analysed by using different types and dosages of zeolites to reduce production temperature to $145^{\circ} \mathrm{C}$ and $120^{\circ} \mathrm{C}$. Thus, for this study, the following mixtures were considered: three asphalt mixtures (WMA-Z1, manufactured with Zeolite 1; WMA-Z2, manufactured with Zeolite 2; and WMA-RZ, manufactured with the Reference Zeolite) manufactured at low temperatures $\left(145^{\circ} \mathrm{C}\right.$ and $\left.120^{\circ} \mathrm{C}\right)$, and different dosages of the three types of zeolite were analysed $(0.1 \%, 0.3 \%$, and $0.5 \%$ over the total weight of the asphalt mixture); and a conventional asphalt mixture (without using zeolites) that was manufactured at the routine temperature of HMA $\left(165^{\circ} \mathrm{C}\right.$, used as a control) and at low temperatures $\left(145^{\circ} \mathrm{C}\right.$ and $120^{\circ} \mathrm{C}$ ) to assess the influence of zeolites (these latter mixtures are referred to in this paper as WMA-R). 
TABLE 3: Main physical and mechanical characteristics of the HMA used as a control.

\begin{tabular}{lc}
\hline Properties & AC 22 35/50 S \\
\hline Optimal bitumen content (\% over mix weight) & 4.03 \\
Bulk density $\left(\mathrm{mg} / \mathrm{m}^{3}\right)$, EN 12697-6 & 2.477 \\
Air void content $(\%)$, EN 12697-8 & 4.1 \\
Aggregates void content (\%), EN 12697-8 & 13.7 \\
Filler/bitumen ratio & 1.0 \\
Marshall stability (kN), EN 12697-34 & 17.79 \\
Marshall deformation (mm), EN 12697-34 & 4.1 \\
\hline
\end{tabular}

The designing factors of WMA were defined in base to the common use of conventional zeolites (as that used as a reference in this study) and following previous studies focused on using zeolites for WMA as indicated in a literature revision done by Woszuk and Franus [16].

2.2. Testing Plan. The testing plan was divided into three different stages: (i) characterization of the various types of zeolite for their application in WMA; (ii) study of the main design factors for WMA including the zeolite by-products as the bitumen foaming agent; (iii) and analysis of the mechanical performance of the WMA manufactured with the zeolite by-products, in comparison with the conventional HMA. Table 4 summarises the testing plan used in the present study.

In the first stage, the characterization process of the zeolite by-products consisted of analysing their capacity for water absorption and release under different temperatures and periods of time, comparing the results of the two types of zeolite by-products (Zeolite 1 and Zeolite 2) with that recorded for the commercial zeolite used as a control. This test consisted of storing three 30-gram samples of each type of zeolite (previously dehydrated) in a climatic chamber under controlled temperature $\left(23 \pm 1^{\circ} \mathrm{C}\right)$ and humidity $(98 \pm 1 \%)$, measuring water absorption after $1,2,3,5,72,98$, 120,240 , and 408 hours. Later, these same samples (partially moistened) were stored in an oven at different temperatures $\left(120^{\circ} \mathrm{C}, 130^{\circ} \mathrm{C}\right.$, and $145^{\circ} \mathrm{C}$, which correspond to WMA manufacturing temperature) to measure the capacity of each material to release its water content during different periods of time.

In the second stage, various asphalt mixtures (all type AC-22S) were tested including a different quantity of each zeolite $(0 \%$ in the cases of HMA and WMA-R, and $0.1 \%$, $0.3 \%$, and $0.5 \%$ in the cases of WMA-Z1, WMA-2, and WMA-RZ) under various manufacturing temperatures $\left(145^{\circ} \mathrm{C}\right.$ and $120^{\circ} \mathrm{C}$, as well as $165^{\circ} \mathrm{C}$ for the conventional HMA without zeolites), with the aim of defining the optimal design of the WMA produced by bitumen foaming through the use of zeolite by-products. To analyse the effect of these parameters, firstly, the workability and compactibility (these properties are essential in asphalt mixtures at low temperatures) of each mixture were evaluated by using a gyratory compactor (up to 210 gyros), which has been proven to be effective to measure the influence of additives in mixture manufacturing [12]. Following this, the indirect tensile strength (EN 12697-23) and bearing capacity (through the stiffness modulus test, EN 12697-26 annex C) were measured at $20^{\circ} \mathrm{C}$ for the specimens ( 4 for each mixture) obtained from the gyratory compactor, with the objective of determining the cohesiveness and coating of each mixture. Based on the results obtained in these tests, the optimal manufacturing temperature and amount of zeolite byproducts (Zeolite 1 and Zeolite 2) were selected for each mixture.

In the third stage of this study, the mechanical behaviour (in both short and long terms) of WMA manufactured with the optimal design for each zeolite by-product was compared with that recorded for conventional HMA in order to assess the viability of using such WMA in the construction of pavements for roads. For this purpose, the tests conducted were the water sensitivity test (EN 12697-12), wheel tracking test (EN 12697-22), and triaxial test (EN 12697-25 method B) at $60^{\circ} \mathrm{C}$, stiffness modulus at different temperatures $\left(5^{\circ}\right.$, $20^{\circ}$, and $40^{\circ} \mathrm{C}$ ) (EN 12697-26 annex C), and UGR-FACT [18], which is an appropriate test for measuring the resistance of asphalt to fatigue cracking. This latter test was also conducted at $10^{\circ} \mathrm{C}, 20^{\circ} \mathrm{C}$, and $30^{\circ} \mathrm{C}$ since temperature plays an essential role in the performance of bituminous materials $[19,20]$. This test was also carried out under stresscontrolled conditions (cyclic loading with a stress amplitude of $0.8 \mathrm{MPa}$ and a frequency of $5 \mathrm{~Hz}$ ) in order to simulate the real conditions usually endured by the pavement, along with the effects of high-speed traffic.

\section{Results and Discussion}

3.1. Stage 1. Characterization of Zeolite for Its Use in WMA. Figure 1 displays the increase in the percentage of humidity (water absorption capacity) as a function of storage time in a climatic chamber (at $98 \%$ of humidity) of the zeolites studied. The results show that, at short time periods (less than 10 hours), all types of zeolite present a similar capacity to absorb water, showing values of humidity around 3-4\% with a coefficient of variation around $20 \%$. However, for longer time periods, the zeolite of reference absorbed close to $10 \%$ and $20 \%$ of water at $100 \mathrm{~h}$ and $400 \mathrm{~h}$, respectively, while the by-products (Zeolite 1 and Zeolite 2) presented values around $7-8 \%$ and $12-13 \%$ for the same periods. This indicates that the zeolite wastes recorded lower percentages of humidity, particularly from a time of 100 hours, this effect being more pronounced for Zeolite 2, which generally presented values near $1-2 \%$ lower than the Zeolite 1 . This therefore suggests that Zeolite 1, which presents lower particle size and then higher specific surface, could be more effective for bitumen foaming than Zeolite 2 since higher water content could be provided during the mixing process.

Figure 2 displays the development of humidity content of each zeolite under different temperatures in order to evaluate its capacity to release water molecules. It is clear that temperature plays an essential role in the phenomenon of water release (which directly affects the foaming process). All types of zeolite released most of its water content during the first 30 minutes at $145^{\circ} \mathrm{C}$, passing from values of humidity close to $40 \%$ for the zeolite reference and $30 \%$ for the by-products, to percentages near 10 (regardless the type of 
TABle 4: Testing plan.

\begin{tabular}{|c|c|c|c|c|}
\hline Study step & Mixtures & Zeolites & $\begin{array}{l}\text { Manufacturing } \\
\text { temperature }\left({ }^{\circ} \mathrm{C}\right)\end{array}$ & Tests \\
\hline Zeolite characterization & - & $\begin{array}{c}\text { Zeolite } 1 \\
\text { Zeolite } 2 \\
\text { Reference Zeolite }\end{array}$ & - & $\begin{array}{l}\text { (i) Water absorption } \\
\text { (ii) Water release }\end{array}$ \\
\hline \multirow{5}{*}{ Design of WMA } & HMA & - & 165 & \multirow{5}{*}{$\begin{array}{l}\text { (i) Workability } \\
\text { (ii) Stiffness modulus at } 20^{\circ} \mathrm{C} \\
\text { (iii) Indirect tensile strength }\left(20^{\circ} \mathrm{C}\right)\end{array}$} \\
\hline & WMA-R & - & $145-120$ & \\
\hline & WMA-Z1 & $0.1-0.3-0.5 \%$ Zeolite 1 & $145-120$ & \\
\hline & WMA-Z2 & $0.1-0.3-0.5 \%$ Zeolite 2 & $145-120$ & \\
\hline & WMA-RZ & $0.1-0.3-0.5 \%$ Reference Zeolite & $145-120$ & \\
\hline \multirow{3}{*}{ Performance of WMA } & HMA & - & 165 & \multirow{3}{*}{$\begin{array}{l}\text { (i) Water sensitivity } \\
\text { (ii) Stiffness modulus at } 5-20^{\circ} \mathrm{C}-40^{\circ} \mathrm{C} \\
\text { (iii) Wheel tracking } \\
\text { (iv) Triaxial } \\
\text { (v) UGR-FACT }\end{array}$} \\
\hline & WMA-Z1 & Optimal \% Zeolite 1 & Optimal & \\
\hline & WMA-Z2 & Optimal \% Zeolite 2 & Optimal & \\
\hline
\end{tabular}

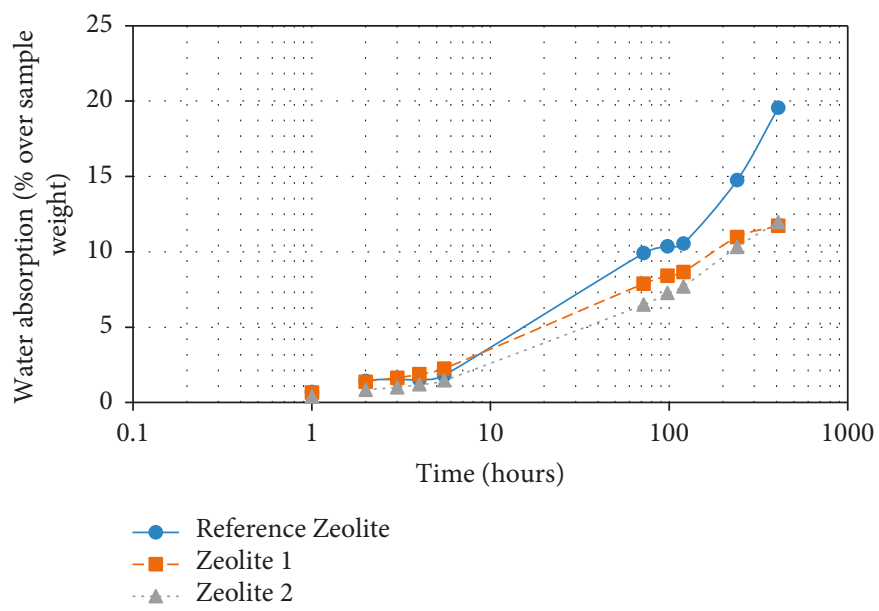

FIGURE 1: Evolution of water absorption capacity of zeolites.

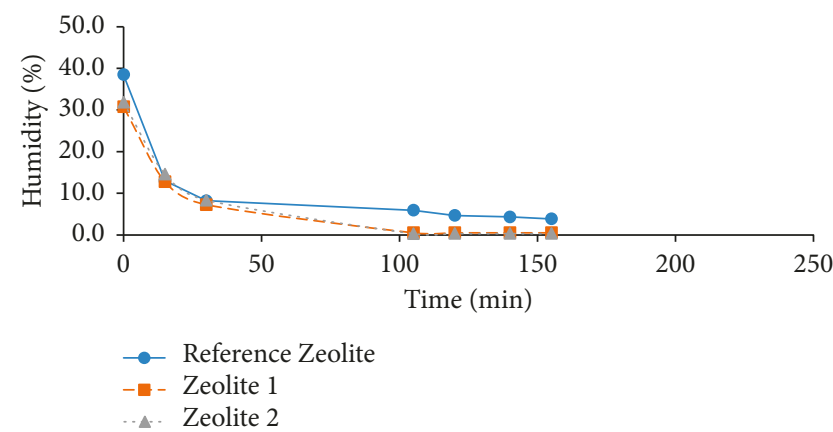

(a)

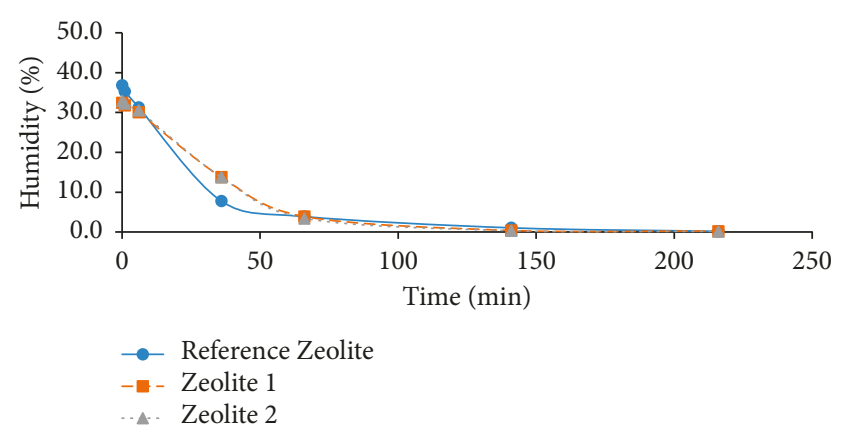

(b)

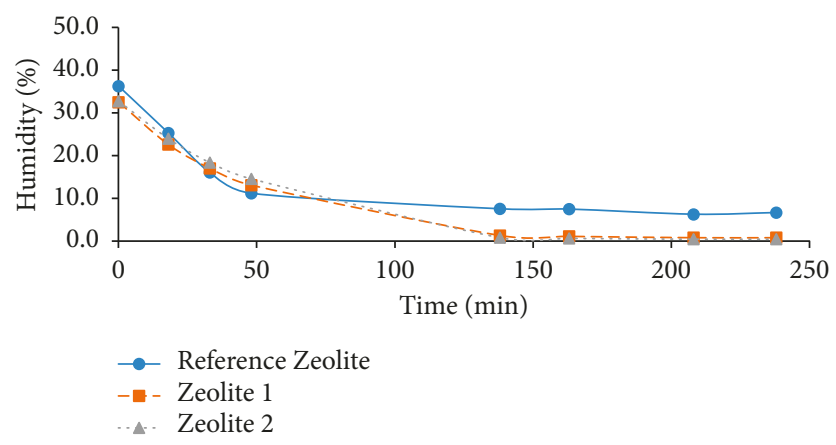

(c)

Figure 2: Evolution of the capacity of zeolites to release water at different temperatures: (a) $145^{\circ} \mathrm{C}$; (b) $130^{\circ} \mathrm{C}$; (c) $120^{\circ} \mathrm{C}$. 
material) with a coefficient of variation lower than $15 \%$. However, to obtain such reduction in humidity content (water release) at a temperature of $120^{\circ} \mathrm{C}$, the required time exceeded 50 minutes (coefficient of variations lower than $15 \%)$, which indicates that, at higher temperatures, the foaming process will proceed more rapidly than at lower temperatures. These results are in accord with those of previous studies suggesting that the release of zeolite water is not a sudden process, but a long-term phenomenon that decreases gradually the binder viscosity and improves the workability during mix asphalt production, placement, and compaction [21].

Regarding the influence of the type of zeolite, the Reference Zeolite showed higher values of humidity at long term, particularly at $120^{\circ} \mathrm{C}$ where this material presented values around $7 \%$ after 150 minutes while the by-products recorded percentages lower than 1 . This could lead to a more prolonged foaming phenomenon than in the case of the zeolite by-products (both showing similar behaviour). Nonetheless, it is seen that all zeolites present comparable behaviour (for the different temperatures analysed) over a short time interval (around 50-100 minutes) when most of the water is released during mixture production and placement, which allows for the improvement of workability and compaction.

3.2. Stage 2. Design of WMA including Zeolite By-Products for Indirect Bitumen Foaming. Figure 3 displays the final air void content (including error bars with deviation values) recorded in the workability study for the different mixtures in order to select the most appropriate design parameters for WMA (zeolite dosage and manufacturing temperature), according to the densification capacity of the WMA. These results suggest that the decrease in manufacturing temperature leads to a significant reduction in mixture densification, passing from content in air void around 3.1\% for the HMA (deviations lower than $0.4 \%$ ) to values higher than $5.1 \%$ for the WMA at $120^{\circ} \mathrm{C}$ without additives (WMA-Reference). This demonstrates the remarkable influence of this factor in the production of these mixes.

However, the use of zeolite (regardless of the type) generally allows for increasing the workability of the material at low temperatures and facilitates its compaction, obtaining in most of the cases lower percentage of voids than the reference mixture at low temperatures (generally, lower than 4.5\% for the WMA at $145^{\circ} \mathrm{C}$ and lower than $5.1 \%$ when the manufacturing temperature was close to $120^{\circ} \mathrm{C}$ ). Also, results showed that the use of zeolites led to values close to those from the conventional HMA, particularly for the mixtures at $145^{\circ} \mathrm{C}$. This, which is in agreement with other authors $[16,22,23]$ who have demonstrated the improvement in WMA workability with zeolites, could lead to economic and environmental benefits associated with lower energy consumption during manufacturing of WMA, lower emissions, and longer transportation distances, without significant reduction in mixture compaction.

Regarding the influence of the dosage of zeolite, the results indicate that (for all types of zeolite) the increase in percentage from $0.1 \%$ to $0.3 \%$ generally translates to lower void content (which could be associated with a more effective foaming process, and then, higher densification of the material), obtaining quite similar effect in the mixtures with the zeolite by-products to that recorded for the case with Reference Zeolite (WMA-RZ). However, it was seen that the use of a dosage of $0.5 \%$ zeolite leads to a decrease in compatibility in most of the mixtures (particularly at $120^{\circ} \mathrm{C}$ ), which could be related to excessive use of these materials as indicated by other authors $[12,24,25]$. Therefore, it appears that $0.3 \%$ of zeolite generally leads to the highest values of density (lowest air void content) regardless of the manufacturing temperature, with zeolite by-products (WMA-Z1 and WMA-Z2) yielding broadly comparable values to WMA-RZ and particularly at a mixing temperature of $145^{\circ} \mathrm{C}$.

Taken together, these findings suggest the viability of using these subproducts to manufacture WMA with appropriate workability properties, without important differences between the types of zeolite used as indicated by other authors [12] who indicated that the compaction temperature and additive dosage have greater effect than the type of zeolite in the densification of the material.

Figure 4 represents the stiffness modulus measured at $20^{\circ} \mathrm{C}$ for the specimens that were obtained from the workability analysis for all the mixtures. Results showed values near 7,000 $\mathrm{MPa}$ (deviations lower than $350 \mathrm{MPa}$ ) for the conventional HMA while the reduction in temperature led to modulus around $5,800 \mathrm{MPa}$ and $4,000 \mathrm{MPa}$ for the mixture without zeolites at $145^{\circ} \mathrm{C}$ and $120^{\circ} \mathrm{C}$ (deviations near $400 \mathrm{MPa}$ for both cases), respectively. However, the use of zeolites, generally led to higher values for such manufacturing temperatures (obtaining even results near the conventional HMA for the WMA at $145^{\circ} \mathrm{C}$ ), presenting limited differences between the cases with zeolite wastes and the reference.

Therefore, the results again indicate that the behaviour of conventional asphalt mixtures is somewhat susceptible to manufacturing temperature while the use of zeolite generally allows for reducing the negative effect of reducing manufacturing temperature on mixture performance, which is in consonance with other studies [12]. This trend is particularly marked in the case of a dosage of $0.3 \%$ zeolite (except in the case of WMA-RZ), which generally appears to be more effective. Also, it was seen that the improvement in the performance of the mixtures with zeolite by-products was comparable to the cases with Reference Zeolite (WMARZ), mainly for the Zeolite 1, which could be considered as more appropriate to increase the bearing capacity of WMA, primarily at $145^{\circ} \mathrm{C}$.

Nonetheless, it must be taken into account that the majority of these mixtures recorded lower values of stiffness modulus than the conventional HMA, particularly in the case of WMA manufactured at $120^{\circ} \mathrm{C}$ that presented the lowest values of bearing capacity. This fact could be linked to the slight increase in void content in comparison to HMA, but also to the lower ageing and oxidation of bitumen when reducing mixing temperature [26], resulting in more viscous and less rigid materials. This phenomenon-in spite of the 


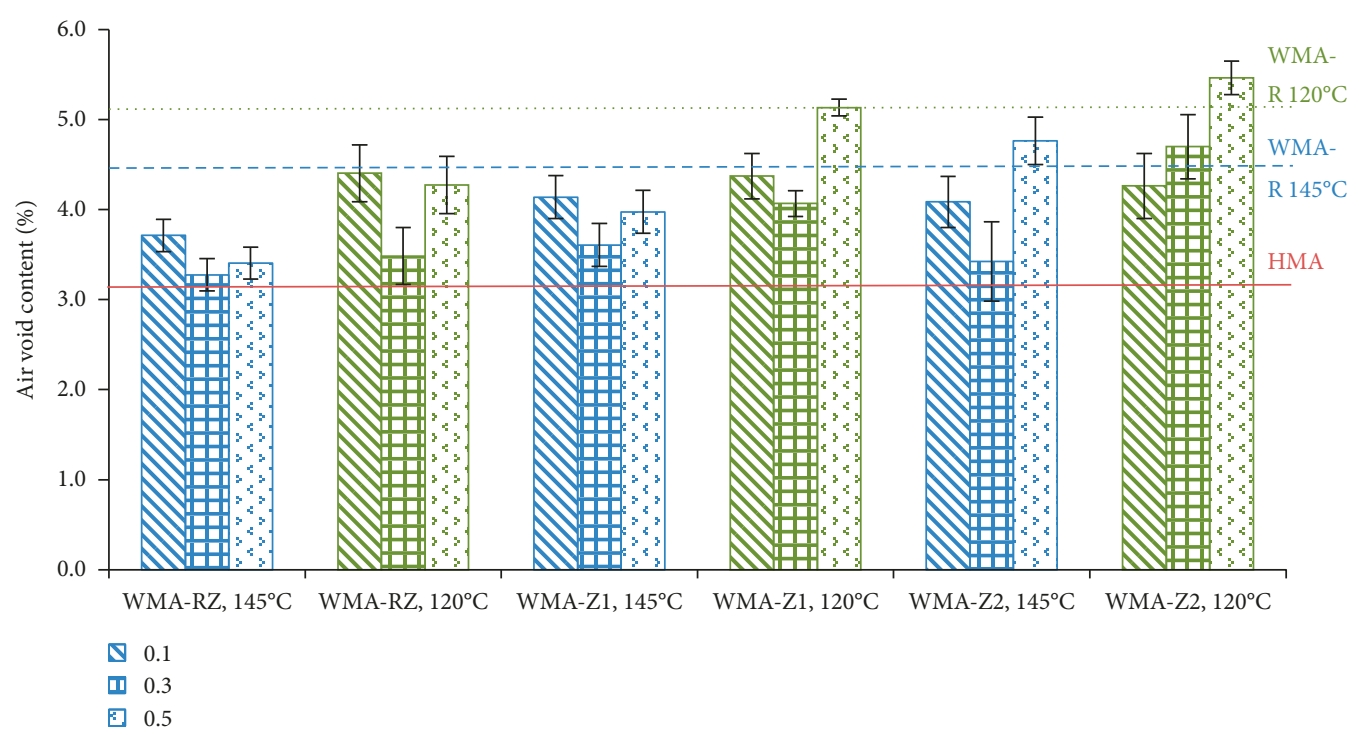

FIgURE 3: Influence of zeolite dosage and type on WMA workability and compactibility.

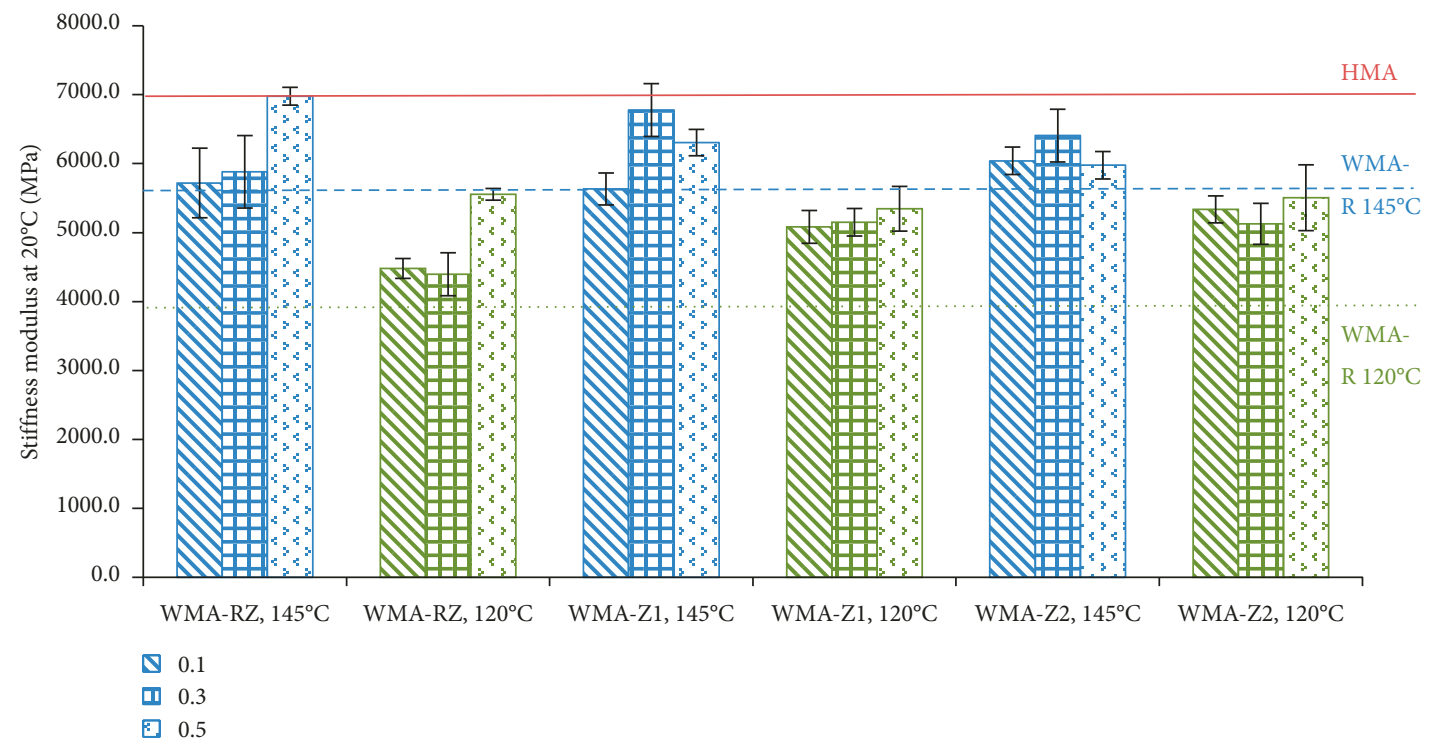

FIGURE 4: Results of the stiffness modulus from the specimens obtained in the workability study.

slight decrease in the stiffness modulus - could lead to longer service life of the material and higher resistance to cracking since it has been shown that less aged bitumen allows for a higher capacity to absorb distresses that occur in road pavements [4].

To understand the effect of zeolite on cohesiveness and coating of WMA, values of indirect tensile strength are shown in Figure 5. As observed previously, results demonstrate that the use of zeolites allows for values of ITS (indirect tensile strength) even higher than $1,600 \mathrm{kPa}$ (which was the result for the HMA, with deviations lower than $70 \mathrm{kPa})$.

Regarding the effect of the type of zeolite by-products, results indicate that WMA with both subproducts recorded values quite similar to those measured for the WMA with the Reference Zeolite. Nonetheless, in agreement with other authors [23], it must be considered that while reducing the mixing temperature lower than $140-145^{\circ} \mathrm{C}$, a significant reduction in ITS can take place, particularly for high dosages of zeolite (higher than $0.5 \%$ ). The negative effect of using high quantities of zeolite on ITS values (particularly with zeolite by-product) could be related to the lower cementing power of these materials while other studies $[12,24]$ have also shown that an excessive amount of water could lead to a loss of adhesion between aggregates and binder.

Therefore, these results confirm that the use of both types of zeolite by-products could lead to the adequate coating of aggregates by bitumen (probably due to the improvement in workability of the WMA when zeolite by-products are used), particularly when using a dosage of $0.3 \%$ at $145^{\circ} \mathrm{C}$ which allowed for comparable results to those with Reference Zeolite. 


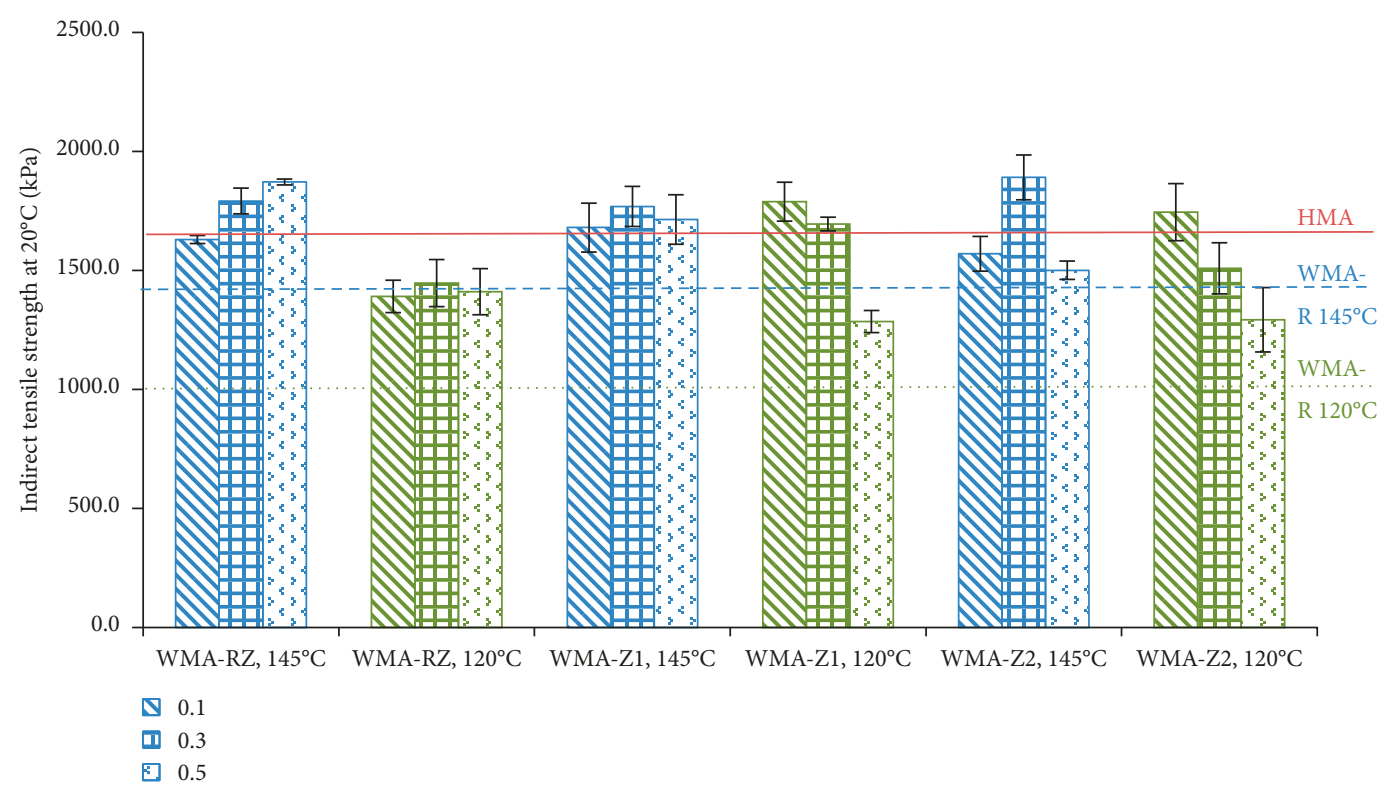

Figure 5: Effect of zeolite type and dosage on indirect tensile strength of WMA.

3.3. Stage 3. Mechanical Performance of WMA with Zeolite ByProducts. In this stage, the mechanical performance of WMA manufactured at $145^{\circ} \mathrm{C}$ with $0.3 \%$ of each type of zeolite by-product is compared with that measured for conventional HMA produced at $165^{\circ} \mathrm{C}$. These design parameters for the WMA were selected according to the results obtained in the previous stages (Table 5 lists the mean results of workability and their deviation for such WMA with zeolite wastes in comparison with the HMA), which show that it is possible to obtain comparable values of density, bearing capacity, and indirect tensile strength.

Figure 6 displays the results obtained on the water sensitivity test for the different mixtures, showing the indirect tensile strength for both dry and wet set of specimens, as well as the ratio of restrained strength (ITSR: indirect tensile strength ratio). Based on results, it is proven that the WMA with zeolites presented lower values of ITSR index (84.9\% for the case with Zeolite 1 and $78.0 \%$ for Zeolite 2 ) than the traditional HMA $87.3 \%$. This is in consonance with other studies $[12,16,23]$ that have found that WMA with zeolites presents a reduction in ITSR around 5-8\%. This could be associated with lower cohesiveness and adhesion between aggregates and bitumen due to the decrease in manufacturing temperature but also to lower interaction between the binder and the zeolites included during the mixing process.

Nonetheless, results indicate that WMA with Zeolite 1 (WMA-Z1) led to values of tensile strength comparable to those for HMA, for both wet and dry conditions, and then, this mixture presented only slight reduction in resistance to water action. However, Zeolite 2 (WMA-Z2) did lead to a higher reduction in mixture strength, particularly for the specimens in contact with water, which reflects lower values of retained strength, and thus higher susceptibility to water action. Therefore, Zeolite 1 could be more effective during the bitumen foaming process (probably associated with its higher capacity to absorb water because of the smaller particles) used to produce WMA with lower susceptibility to water action.

Figure 7 shows the influence of in-service temperature on the bearing capacity of the WMA with both subproduct zeolites and the HMA. It can be seen that the reduction in the stiffness modulus when increasing the temperature is broadly similar for all the mixtures studied, which indicates comparable susceptibility of its bearing capacity to climatic gradients. Nonetheless, the results show that the WMA with Zeolite 2 presented values near those for HMA, while the Zeolite 1 (WMA-Z1) presented even higher stiffness values, which could be associated with the improvement in workability due to the foaming process induced by the use of this type of zeolite. These results are in accord with those found in previous studies on the effect of zeolites on the dynamic modulus of WMA compared with HMA [27].

To analyse the resistance of the mixture to permanent deformations, Figure 8(a) displays the results obtained in the wheel tracking test (depth of rut and slope of the curve of plastic deformations), while Figure 8(b) represents the results of the triaxial test: final permanent deformation (as a percentage of strain in reference to the initial height of the specimen) and slope of creep deformation and creep modulus.

In all cases, the results show that WMA with Zeolite 1 (WMA-Z1) presents quite similar values of final deformation at the end of the tests to those measured for the conventional HMA, while also showing a reduced tendency towards long-term rutting. This can be taken to indicate that this asphalt mixture offers resistance to permanent deformations comparable to HMA, which is in consonance with some authors [22] who state that WMA with zeolite reduce susceptibility to rutting, making it suitable for application in road pavements. However, also in agreement with other studies [28] where other types of zeolites are used, the application of the other kinds of zeolite by-product (Zeolite 2, WMA-Z2) results in a WMA with lower 
TABLE 5: Comparative summary of results from the workability study.

\begin{tabular}{lcccccc}
\hline \multirow{2}{*}{ Property } & \multicolumn{2}{c}{ HMA } & \multicolumn{2}{c}{ WMA-0.3\% Z1, $145^{\circ} \mathrm{C}$} & \multicolumn{2}{c}{ WMA-0.3\% Z2, $145^{\circ} \mathrm{C}$} \\
& Mean & Deviation & Mean & Deviation & Mean & Deviation \\
\hline Air void (\%) & 3.4 & 0.45 & 3.6 & 0.72 & 3.4 & 0.75 \\
Stiffness at $20^{\circ} \mathrm{C}$ & $6,956.0$ & 329.1 & $6,778.4$ & 382.9 & $6,407.1$ \\
ITS at $20^{\circ} \mathrm{C}$ & $1,610.2$ & 66.5 & $1,769.0$ & 84.2 & $1,891.8$ & 382.3 \\
\hline
\end{tabular}

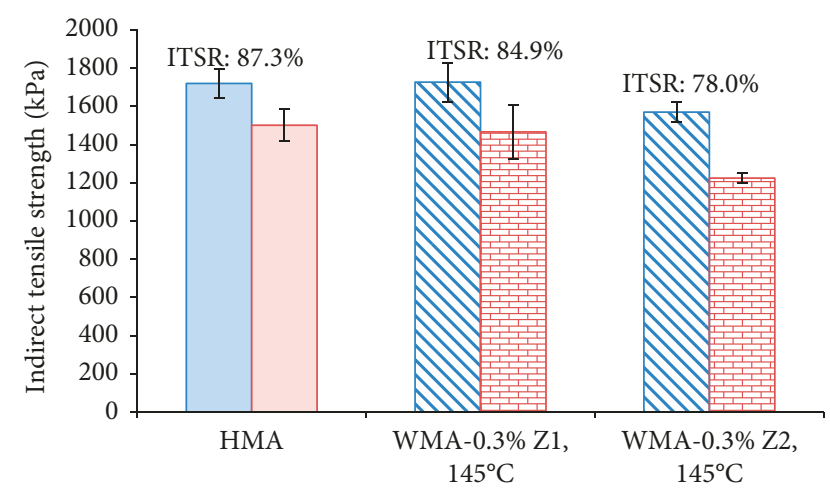

$\checkmark$ Dry set

$\square$ Wet set

FIgURE 6: Results of the water sensitivity test for HMA and WMA with subproduct zeolite.

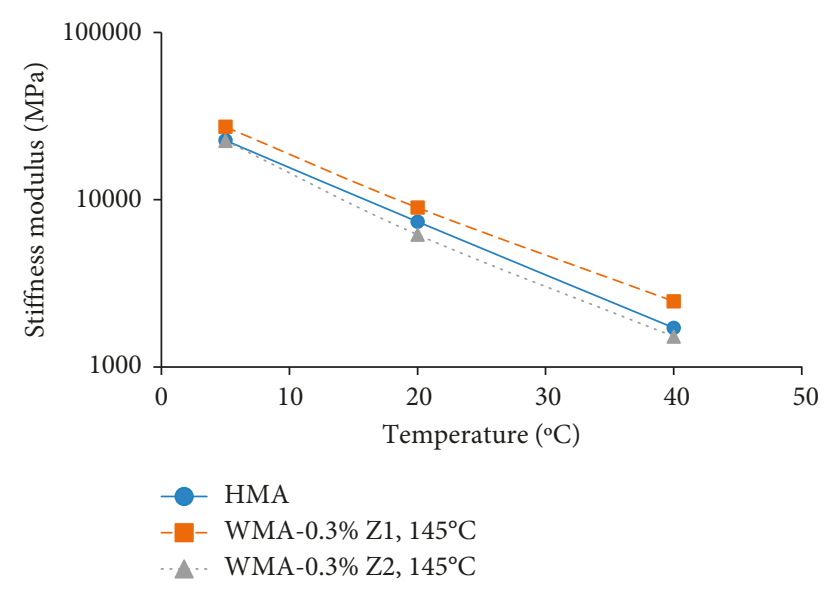

Figure 7: Stiffness modulus at different temperatures for both HMA and WMA with zeolites.

resistance to creep (lower modulus and ratio of creep) and thus a higher susceptibility to form rut deformations during its application in road pavements. This fact could be related to the higher size of particles in Zeolite 2 and their lower capacity to absorb water (and then, lower effectiveness for the foaming process) as seen in the characterization study of these materials.

Therefore, it can be said that the type of zeolite can lead to different behaviour under permanent deformations, where, in this study, Zeolite 1 could be the preferable option for obtaining WMA with higher resistance to rutting, showing comparable performance to HMA.

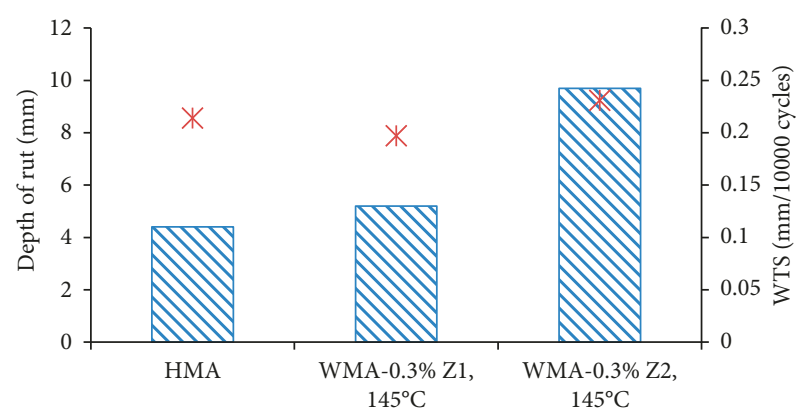

$\mathbb{N}$ Depth of rut

* WTS

(a)

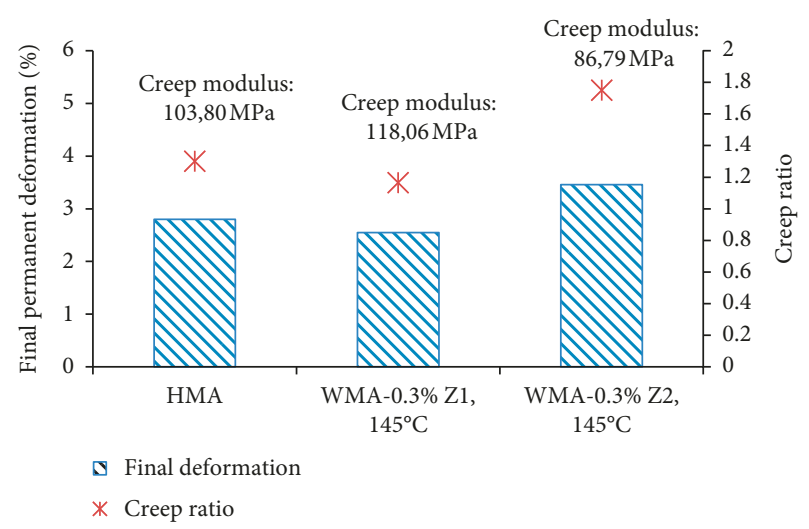

(b)

FIGURE 8: Resistance to plastic deformations measured by the wheel tracking test (a) and the triaxial test (b).

With the aim of evaluating the WMA in terms of resistance to cracking and fatigue life in comparison with conventional HMA, Figure 9 represents the values of mean damage parameter for the different mixtures under various testing temperatures. This parameter is used to quantify the susceptibility of mixtures to fatigue as an average of the energy dissipated per cycle due to the damage induced in the material [29], and therefore, the higher the parameter, the higher the damage in the material, reducing its fatigue life.

These results confirm that WMA-Z1 again presents comparable mechanical performance to conventional HMA, with higher resistance to cracking fatigue than the WMA-Z2, which shows higher values of damage than the other two mixtures analysed, and thus lower number of cycles are required to cause material failure. The results also show that the WMA presented similar thermal susceptibility to HMA, which implies that the warm mixtures and HMA would show comparable performance under different climate 


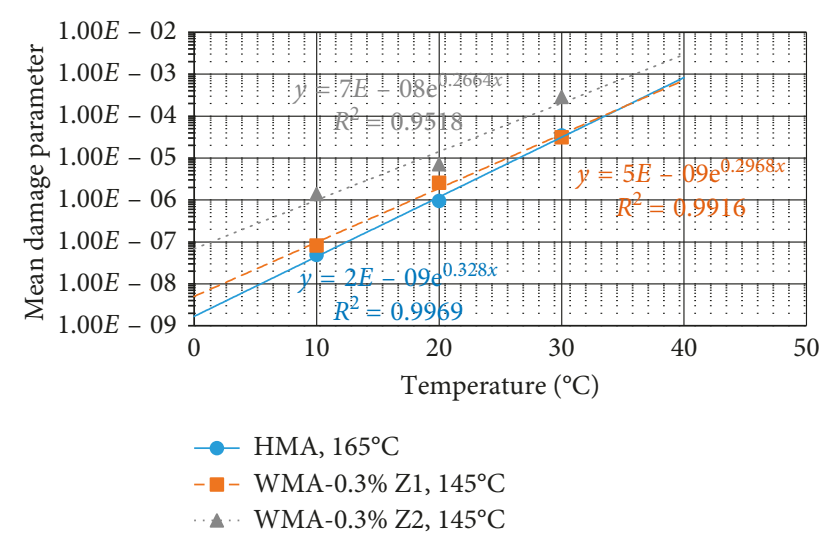

FIgURE 9: Mean damage parameter for the different mixtures under various testing temperatures.

conditions that can occur during the service life of the pavement.

\section{Conclusions}

This study aims to examine the viability of using industrial zeolite by-products (obtained from the petroleum refining process) in the manufacturing of WMA by the technique of indirect bitumen foaming. For this purpose, these byproducts were characterized according to their application, while the design and evaluation of the mechanical performance of WMA that included these by-products was compared with that of traditional hot mix asphalts (HMAs). From the results obtained in this study, the following conclusions can be drawn:

(i) Zeolite by-products (particularly Zeolite 2) showed a slightly lower capacity to absorb water than the commercial by-product, which should be taken into account during the design and manufacturing stages of WMA. Nonetheless, the speed at which the various zeolites release the majority of the water content was comparable across a range of temperatures tests, if it is considered that water release is slower at lower temperatures. This means that zeolite by-products can be applied in a similar way to the conventional zeolites that are widely used in WMA.

(ii) The use of $0.3 \%$ of zeolite by-products allowed obtaining mixtures with similar workability and mechanical performance to that measured for the WMA with Reference Zeolite at $120^{\circ} \mathrm{C}$ and $145^{\circ} \mathrm{C}$, particularly in the case of the last manufacturing temperature when obtaining even comparable results to those recorded for the conventional HMA.

(iii) WMA manufactured with Type 1 Zeolite byproducts (Zeolite 1) presented quite similar performance to HMA in terms of water action, while WMA with Zeolite 2 showed a slight increase in water sensitivity, which could be associated with lower adhesiveness and cohesion when this additive is used. (iv) The WMA manufactured with Zeolite 1 also recorded similar bearing capacity and resistance to plastic deformations to those measured for the conventional HMA whilst the WMA manufactured with Zeolite 2 showed lower mechanical performance, which could be associated with the lower effectiveness of this type of zeolite in producing bitumen foaming.

(v) Similarly, WMA manufactured with Zeolite 2 presented, across a range of test temperatures, lower resistance to fatigue cracking than that recorded for the WMA produced with Zeolite 1, which showed comparable performance to HMA.

Based on these results, it can be said that Zeolite 1 (which is the by-product with the lower particle size and the higher capacity to absorb water) could be suitable for application in the manufacturing of warm mix asphalts using the technology of indirect bitumen foaming. Use of this technology could bring important economic and environmental benefits to the field of road pavement construction without compromising mechanical performance.

\section{Data Availability}

The data used to support the findings of this study are available from the corresponding author upon request.

\section{Conflicts of Interest}

The authors declare that they have no conflicts of interest.

\section{Acknowledgments}

The present study has been conducted within the framework of the research project entitled "Soluciones de Pavimentación Ecológicamente Sostenibles: Ecoasfaltos" funded by the Ministry of Economy and Knowledge of Andalusia and the Ministry of Economy and Competitiveness of Spain in the framework of CTA (Corporación Tecnológica de Andalucía).

\section{References}

[1] EAPA-European Asphalt Pavements Association, Asphalt in Figures, EAPA, Brussels, Belgium, 2015.

[2] A. Almeida-Costa and A. Benta, "Economic and environmental impact study of warm mix asphalt compared to hot mix asphalt," Journal of Cleaner Production, vol. 112, pp. 2308-2317, 2016.

[3] M. Hassan, "Evaluation of the environmental and economic impacts of warm-mix asphalt using life-cycle assessment," International Journal of Construction Education and Research, vol. 6, no. 3, pp. 238-250, 2010.

[4] F. Moreno-Navarro, M. Sol-Sánchez, G. García-Travé, and M. C. Rubio-Gámez, "Understanding the effects of ageing and temperature on the fatigue cracking resistance of bituminous mixtures," in RILEM Bookseries, vol. 13, Springer, Dordrecht, Netherlands, 2016.

[5] T. Blankendaal, P. Schuur, and H. Voordijk, "Reducing the environmental impact of concrete and asphalt: a scenario 
approach," Journal of Cleaner Production, vol. 66, pp. 27-36, 2014.

[6] L. P. Thives and E. Ghisi, "Asphalt mixtures emission and energy consumption: a review," Renewable and Sustainable Energy Reviews, vol. 72, pp. 473-484, 2017.

[7] M. Pérez-Martínez, F. Moreno-Navarro, J. Martín-Marín, C. Ríos-Losada, and M. C. Rubio-Gámez, "Analysis of cleaner technologies based on waxes and surfactant additives in road construction," Journal of Cleaner Production, vol. 65, pp. 374-379, 2014.

[8] J. Zhang, F. Yang, J. Pei, S. Xu, and F. An, "Viscositytemperature characteristics of warm mix asphalt binder with Sasobit ${ }^{\circledR}$," Construction and Building Materials, vol. 78, pp. 34-39, 2015.

[9] M. Sol-Sánchez, F. Moreno-Navarro, G. García-Travé, and M. C. Rubio-Gámez, "Analysing industrial manufacturing inplant and in-service performance of asphalt mixtures cleaner technologies," Journal of Cleaner Production, vol. 121, pp. 56-63, 2016.

[10] A. Chimicz-Kowalska, W. Gardziejczyk, and M. Iwański, "Moisture resistance and compactibility of asphalt concrete produced in half-warm mix asphalt technology with foamed bitumen," Construction and Building Materials, vol. 126, pp. 108-118, 2016.

[11] A. Sharma and B. K. Lee, "Energy savings and reduction of $\mathrm{CO}_{2}$ emission using $\mathrm{Ca}(\mathrm{OH})_{2}$ incorporated zeolites as an additive for warm and hot mix asphalt production," Energy, vol. 136, pp. 142-150, 2017.

[12] A. Woszuk and W. Franus, "Properties of the warm mix asphalt involving clinoptilolite and Na-P1 zeolite additives," Construction and Building Materials, vol. 114, pp. 556-563, 2016.

[13] S. Chałupnik, W. Franus, M. Wysocka, and G. Gzyl, "Application of zeolites for radium removal from mine water," Environmental Science and Pollution Research, vol. 20, no. 11, pp. 7900-7906, 2013.

[14] W. Franus, "Characterization of X-type zeolite prepared from coal fly ash," Polish Journal of Environmental Studies, vol. 21, no. 2, pp. 337-343, 2012.

[15] M. Wdowin, W. Franus, and R. Panek, "Preliminary results of usage possibilities of carbonate and zeolitic sorbents in $\mathrm{CO}_{2}$ capture," Fresenius Environmental Bulletin, vol. 21, no. 12, pp. 3726-3734, 2012.

[16] A. Woszuk and W. Franus, "A review of the application of zeolite materials in warm mix asphalt technologies," Applied Sciences, vol. 7, no. 3, p. 293, 2017.

[17] F. Xiao, P. E. Wenbin Zhao, and S. N. Amirkhanian, "Fatigue behavior of rubberized asphalt concrete mixtures containing warm asphalt additives," Construction and Building Materials, vol. 23, no. 10, pp. 3144-3151, 2009.

[18] F. Moreno-Navarro and M. C. Rubio-Gámez, "UGR-FACT test for the study of fatigue cracking in bituminous mixes," Construction and Building Materials, vol. 43, pp. 184-190, 2013.

[19] M. Sol-Sánchez, F. Moreno-Navarro, G. García-Travé, and M. C. Rubio-Gámez, "Laboratory study of the long-term climatic deterioration of asphalt mixtures," Construction and Building Materials, vol. 88, pp. 32-40, 2015.

[20] M. R. Taha, S. Hardwiyono, N. I. M. Yusoff, M. R. Hainin, J. Wu, and K. A. M. Nayan, "Study of the effect of temperature changes on the elastic modulus of flexible pavement layers," Research Journal of Applied Sciences, Engineering and Technology, vol. 5, no. 5, pp. 1661-1667, 2013.
[21] J. D’Angelo, E. Harm, J. Bartoszek et al., "Warm-mix asphalt: European practice," Report No. FHWA-PL-08-007, Federal Highway Administration, Alexandria, VA, USA, 2008.

[22] J. De Visscher, F. Vervaecke, A. Vanelstraete, H. Soenen, T. Tanghe, and P. Redelius, "Asphalt production at reduced temperatures using zeolites and the impact on asphalt performance," Road Materials and Pavement Design, vol. 11, no. 1, pp. 65-81, 2010.

[23] E. Sanchez-Alonso, A. Vega-Zamanillo, D. Castro-Fresno, and M. DelRio-Prat, "Evaluation of compactability and mechanical properties of bituminous mixes with warm additives," Construction and Building Materials, vol. 25, no. 5, pp. 2304-2311, 2011.

[24] O. R. Larsen, O. Moen, C. Robertus, and B. G. Koenders, "WAM-foam asphalt production at lower operating temperatures as an environmental friendly alternative to HMA," in Proceedings of the 3rd Eurasphalt \& Eurobitume Congress, Vienna, Austria, May 2004.

[25] R. Vaiana, T. Iuele, and V. Gallelli, "Warm mix asphalt with synthetic zeolite: a laboratory study on mixes workability," International Journal of Pavement Research and Technology, vol. 6, no. 5, pp. 562-569, 2013.

[26] S. W. Goh and Z. You, "Evaluation of warm mix asphalt produced at various temperatures through dynamic modulus testing and four point beam fatigue testing," in Proceedings of the GeoHunan international Conference-Pavements and Materials: Recent Advances in Design, Testing, and Construction, Hunan, China, May 2011.

[27] A. S. M. A. Rahman and R. A. Tarefder, "Dynamic modulus and phase angle of warm-mix versus hot-mix asphalt concrete," Construction and Building Materials, vol. 126, pp. 434-441, 2016.

[28] E. Sanchez-Alonso, A. Vega-Zamanillo, M. A. Calzada-Perez, and D. Castro-Fresno, "Effect of warm additives on rutting and fatigue behaviour of asphalt mixtures," Construction and Building Materials, vol. 47, pp. 240-244, 2013.

[29] F. Moreno-Navarro and M. C. Rubio-Gámez, "Mean damage parameter for the characterization of fatigue cracking behavior in bituminous mixes," Materials \& Design (1980-2015), vol. 54, pp. 748-754, 2014. 


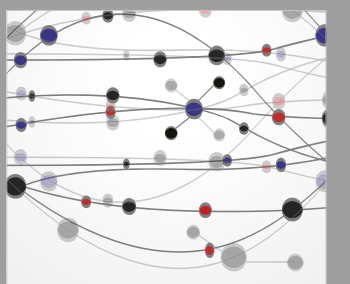

The Scientific World Journal
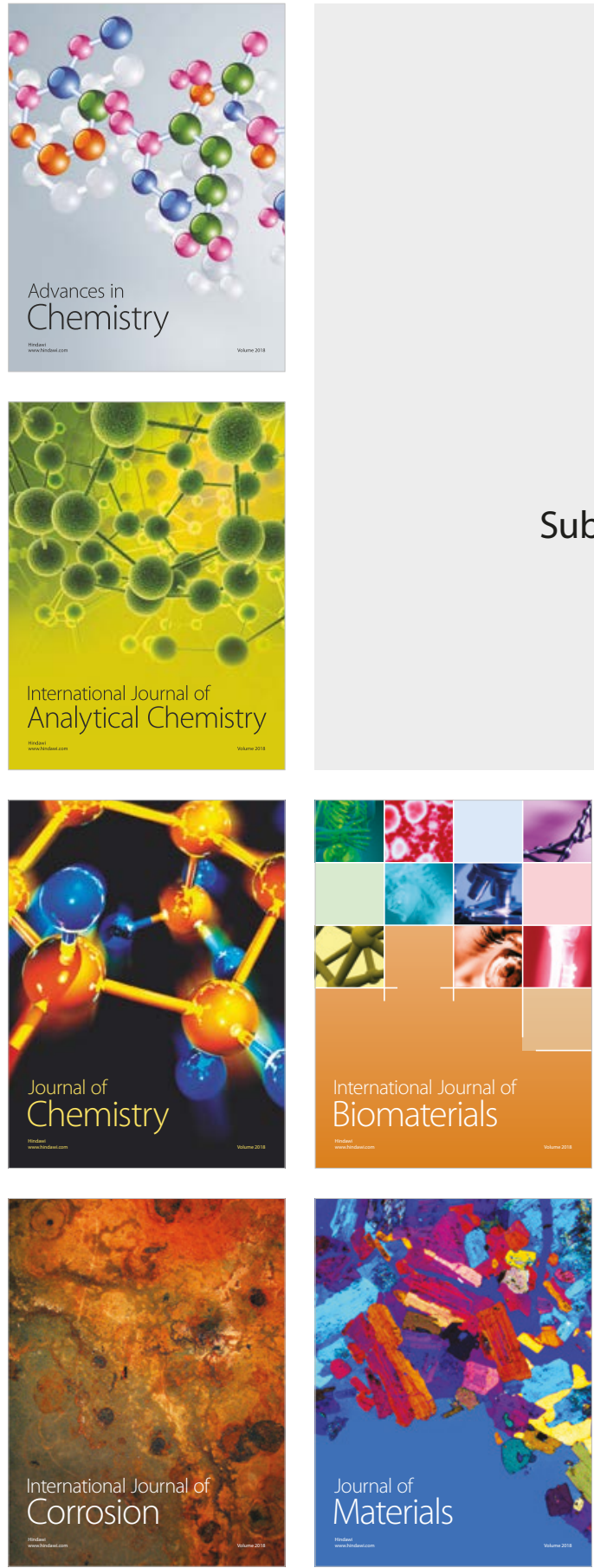

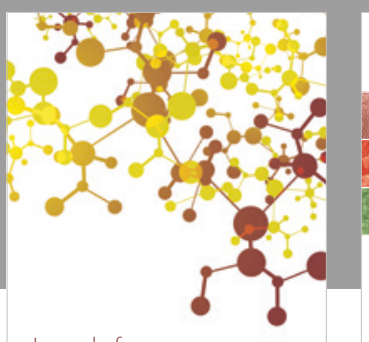

Journal of

Applied Chemistry
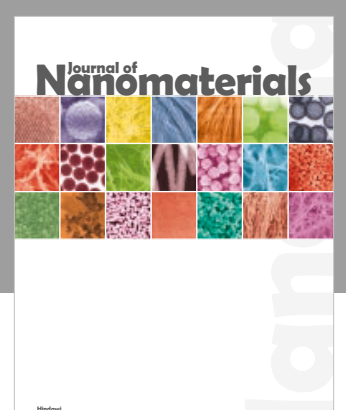

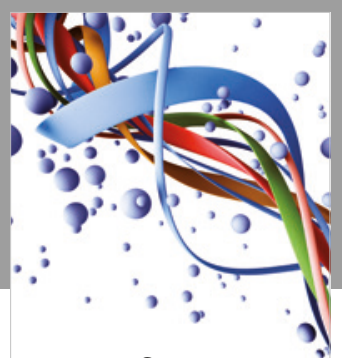

Scientifica

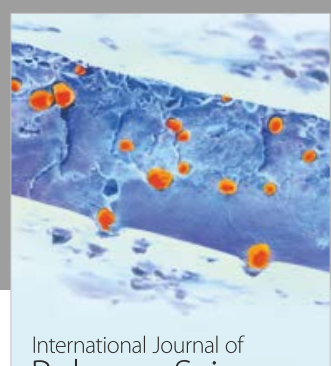

Polymer Science

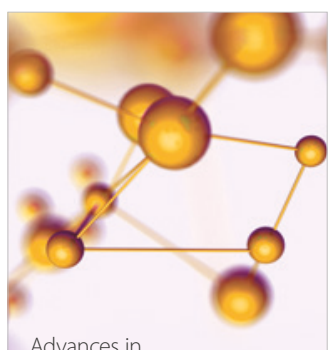

Physical Chemistry
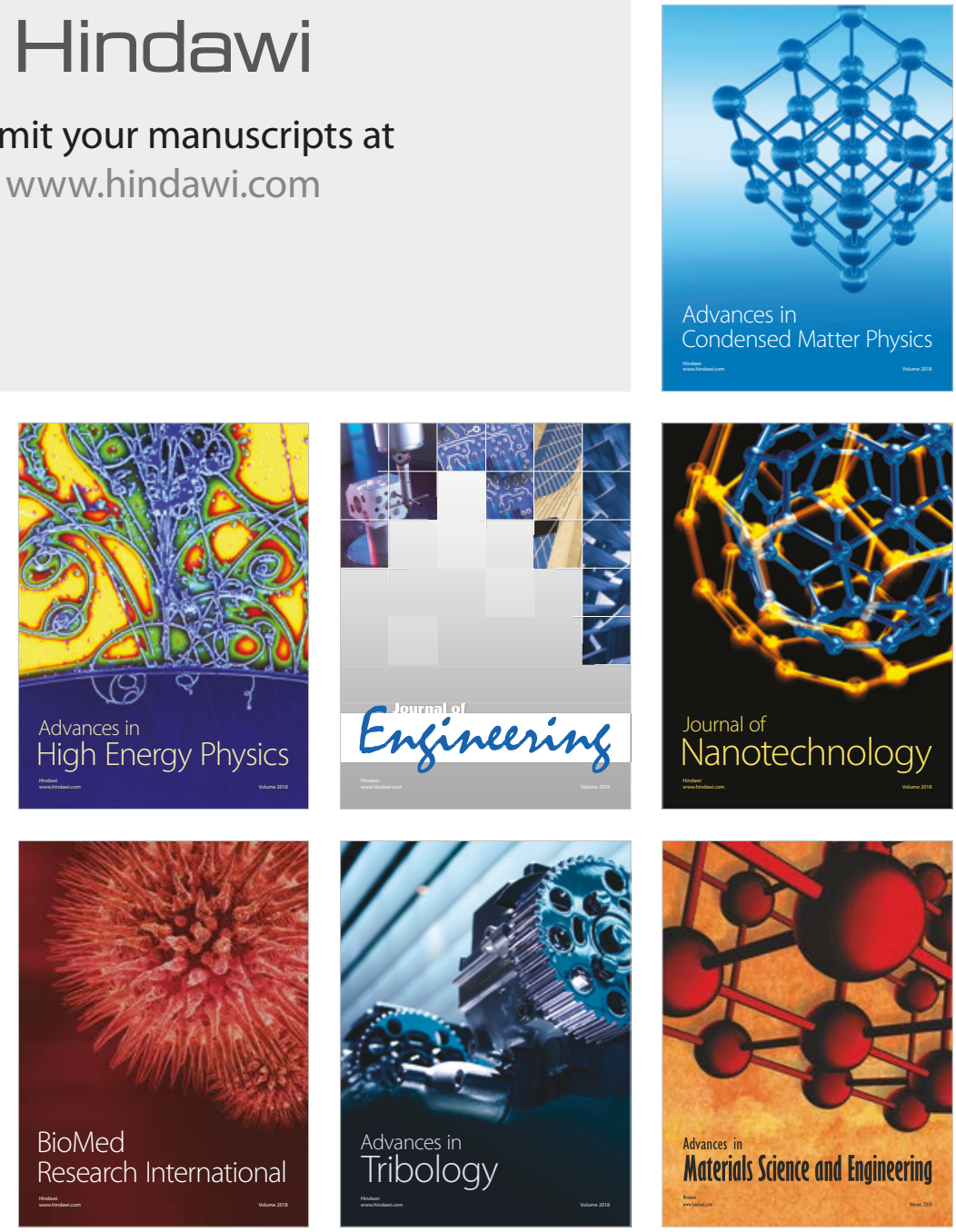